We thank all the people who responded to this survey; Sarah Thorne for data entry; and Janet Darbyshire, Vikki Entwistle, David Girling, Joan Houghton, Richard Lilford, Sandy Oliver, John Stewart, Hazel Thornton, and Sarah Walker for their helpful comments.

Contributors: The survey was suggested by IC. All authors contributed to designing the questionnaire. $\mathrm{BH}$ and $\mathrm{AT}$ conducted the survey. AK designed and developed the database. $\mathrm{DE}, \mathrm{BH}, \mathrm{AK}$, and AT analysed the data. All authors wrote the paper. AT is guarantor for this paper.

Funding: This study was commissioned by Consumers in NHS Research and funded by the Department of Health through the NHS Research and Development Programme.

Competing interests: $\mathrm{BH}$ runs the Consumers in NHS Research Support Unit which is funded by the Department of Health.

1 Grant-Pearce C, Miles I, Hills P. Mismatches in priorities for health research between professionals and consumers. Manchester: Policy Research in Engineering, Science and Technology, University of Manchester, 1998.

2 Tallon D, Chard J, Dieppe P. Relation between agendas of the research community and the research consumer. Lancet 2000;355:2037-40.

3 Marlin A, Redman S, Clarke C, Clark R, Boyle F. Breast cancer research in Australia: current research and future priorities. Kings Cross, NSW: NHMRC National Breast Cancer Centre, 1996.

4 Chalmers I. What do I want from health researchers and research when I am a patient? $B M J 1995 ; 310: 1315-8$
5 Goodare H, Lockwood S. Involving patients in clinical research. BMJ 1999;319:724-5

6 Medical Research Council. Guidelines for good practice in clinical trials. London: MRC, 1998.

7 Association of the British Pharmaceutical Industry. Good clinical (research) practice. London: ABPI, 1992

8 NHS Executive. Research: what's in it for consumers? London: Department of Health, 1998.

9 Hanley B. Involvement works. London: Department of Health, 1999.

10 Carr-Hill R, Dixon P. A database of examples of consumer involvement in research. York: Centre for Health Economics, 1999.

11 Edwards SJL, Lilford RJ, Hewison J. The ethics of randomised controlled trials from the perspectives of patients, the public, and healthcare professionals. BMJ 1998:317:1209-12.

12 Oliver S. Exploring lay perspectives on questions of effectiveness. In: Maynard A, Chalmers I, eds. Non-random reflections on health services research. London: BMJ Publishing, 1997:272-91.

13 Epstein S. Impure science. Berkeley, CA: University of California Press, 1996.

14 Thornton H. CAG-CT: consumers' advisory group for clinical trials. National Centre for Clinical Audit Newsletter 8 May 1998:11-2.

15 Thornton H. Randomised clinical trials: the patient's point of view. In: Silverstein MJ, ed. Ductal carcinoma in situ of the breast. Baltimore: Williams and Wilkins, 1997:433-9.

16 Jadad A. Randomised controlled trials. London: BMJ Books, 1998

17 Chalmers I. A guide to patient-led good controlled trials [letter]. Lancet 2000;356:774.

(Accepted 19 December 2000)

\title{
Management of menorrhagia: an audit of practices in the Anglia menorrhagia education study
}

Guy R K Fender, Andrew Prentice, Richard M Nixon, Tess Gorst, Stephen W Duffy, Nicholas E Day, Stephen K Smith

Menorrhagia is an important healthcare problem for women. ${ }^{1}$ In primary care menorrhagia is a considerable burden on resources and may ultimately lead to referral and surgery. ${ }^{2}$ There is a gap between research and practice, with best evidence not uniformly applied. The Anglia menorrhagia education study, a randomised controlled trial of an educational package delivered in 100 general practices in East Anglia between November 1995 and March 1996, evaluated whether education could change doctors' management. ${ }^{3}$ Practices reported individual cases, and behaviour of practices receiving education was compared with that in control practices. There were differences in the numbers reported from practices, raising concerns that underreporting might impact on the result. The publication of an Effective Health Care bulletin on menorrhagia coinciding with the start of the study was also a potential confounder. ${ }^{4}$ Furthermore, the reported data allowed comparison only between the two study groups and did not allow assessment of previous behaviour. It was therefore felt necessary to audit practice before and after the Anglia study intervention to validate its methods and findings, and to adjust for differences in practices, changes over time, and the effect of confounders.

\section{Subjects, methods, and results}

Four audit standards were set with local medical audit advisory groups: all women with menorrhagia under the age of 40 should receive tranexamic acid before hospital referral; no women should receive norethist- erone as first line treatment for menorrhagia; all women with menorrhagia should receive tranexamic acid or a non-steroidal anti-inflammatory drug as first line treatment; and women under 40 with menorrhagia should be referred only if appropriate medical treatment had been given. Notes of women aged 15-45 who first attended the year before or after the trial started were identified and audited by the study team. Data analysis calculated odds ratios and 95\% confidence intervals with a random effects logistic regression model. ${ }^{5}$ This model compared the odds of referral or treatment in the intervention group of general practices $(n=27)$ with the control group $(n=25)$, adjusting for pre-intervention behaviour and the cluster randomised design of the original Anglia study.

The results are presented as the odds of compliance with standards and absolute prescribing and referral rates from 662 cases of menorrhagia (figure). A woman was almost five times as likely to receive tranexamic acid in practices that received intervention as part of compliance with the standard (odds ratio $4.75 ; 1.42$ to 12.1 ). These women were only half as likely to receive norethisterone as first line treatment $(0.62 ; 0.38$ to 0.92$)$, with women nearly twice as likely to receive appropriate first line treatment $(1.81 ; 1.24$ to 2.53). Women referred from practices that received intervention were more likely to been given appropriate first line medication before referral $(2.87 ; 1.14$ to 6.15). Absolute data show a halving of referrals $(0.537$; 0.34 to 0.81 ), an increase in prescriptions of
Department of
Obstetrics and
Gynaecology,
School of Clinical
Medicine,
University of
Cambridge, Box
223, Rosie Hospital,

BMJ 2001;322:523-4 


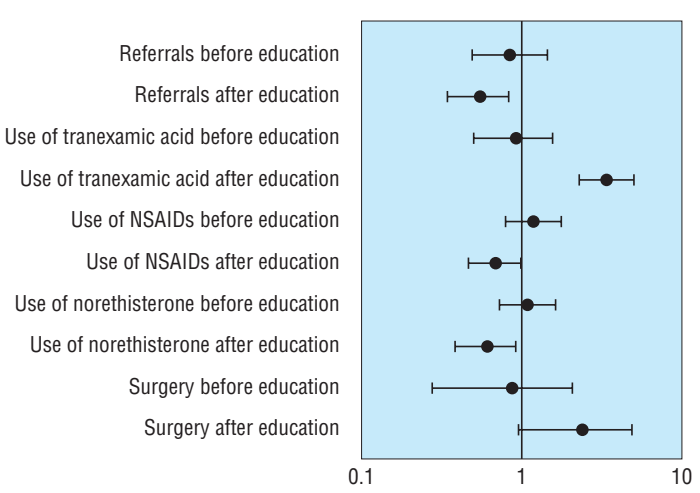

NSAID = non-steroidal anti-inflammatory drug

Odds ratios for various aspects of menorrhagia management both before and after educational intervention. Bars represent 95\% confidence intervals

tranexamic acid ( $3.36 ; 2.21$ to 4.96$)$, and a reduction in norethisterone treatment $(0.67 ; 0.46$ to 0.95$)$ for cases of menorrhagia. Non-steroidal anti-inflammatory drugs were prescribed slightly less commonly in groups receiving intervention $(0.61 ; 0.38$ to 0.90$)$. The odds of hysterectomy in the education group were increased by 2.33 ( 0.94 to 4.87 ). There were no demographic differences between practices.

\section{Comment}

The data show a positive change in behaviour among doctors as a result of education. The results also validate previously reported randomised controlled trial data. ${ }^{3}$ There were no before and after differences in control practices, indicating that external confounders had no effect. The trend towards an increased chance of hysterectomy in intervention groups may be because they had already received appropriate first line treatment. These women may proceed to more appropriate surgery as a result of this intervention.

We thank all general practitioners who participated in the study and the regional postgraduate education office, Anglia and Oxford Health Authority, Fulbourn, Cambridge, without whose assistance it would not have been possible to complete the study.

Contributors: GRKF helped with audit design and implementation, audit management, data collation and analysis, and paper preparation and approval. AP helped with audit design and paper preparation and approval. He is also the guarantor. TG was involved in implementation of the audit, management, data collation and approval. RMN was involved in data collation and analysis and paper preparation and approval. SWD was involved in audit analysis and paper preparation and approval. NED was involved in paper preparation and approval. SKS was involved in paper preparation and approval.

Funding: The project was funded by the NHS Research and Development Health Technology Assessment programme.

Competing interests: None declared.

1 Vessey M, Villard-MacKintosh L, McPherson K, Coulter A, Yeates D. The epidemiology of hysterectomy: findings of a large cohort study. Br J Obstet Gynaecol 1992:99:402-7.

2 Coulter A, Bradlow J, Agass M, Martin-Bates C, Tulloch A. Outcomes of referrals to gynaecology outpatient clinics for menstrual problems: an audit of general practice records. BrJ Obstet Gynaecol 1991;98:789-96.

3 Fender G, Prentice A, Gorst T, Nixon RM, Duffy SW, Day NE, et al Randomised controlled trial of educational package on management of menorrhagia in primary care: the Anglia menorrhagia education study $B M J 1999 \cdot 318 \cdot 1246-50$

4 Effective Health Care: The management of menorrhagia. York: NHS Centre for Reviews and Dissemination, University of York, 1995 (No. 1).

5 Nixon R, Duffy S, Fender GRK, Prevost T, Day N. Randomisation at the level of practice surgery: use of pre-intervention data and random effects models. Statistics in Med (in press).

(Accepted 15 August 2000)

\title{
Violence by clients towards female prostitutes in different work settings: questionnaire survey
}

\author{
Stephanie Church, Marion Henderson, Marina Barnard, Graham Hart
}

Centre for Drug Misuse Research, Glasgow University, Glasgow G12 8SQ Stephanie Church research fellow Marina Barnard senior research fellow

Medical Research Council Social and Public Health Science Unit, University of Glasgow, Glasgow G12 8RZ

Marion Henderson senior researcher

Graham Hart associate director

Correspondence to: S Church Stephanie@msoc. mrc.gla.ac.uk

BMJ 2001;322:524-5
Violence by clients towards prostitutes has seldom been the focus of public and academic interest, yet it is a major health issue. ${ }^{12}$ Concern has mostly focused on the potential of prostitutes to transmit sexual infections, notably HIV, to their clients and subsequently partners. ${ }^{3}$ Features of female prostitution that have a direct impact on the health of prostitutes but not the health of others have therefore tended to be overlooked. The scant research that is available on violence by clients shows that prostitutes who work outdoors in particular routinely confront clients who are verbally, sexually, and physically violent towards them. ${ }^{4}$ We report on the prevalence of violence by clients against female prostitutes working either outdoors or indoors in three major British cities.

\section{Methods and results}

During 1999 three female researchers (SC, MB, and Catherine Benso) contacted 240 female prostitutes; 115 worked outdoors (40 in Leeds, 75 in Glasgow) and 125 worked indoors in saunas or flats $(50$ in Leeds, 75 in Edinburgh). We designed a structured questionnaire using previously validated measures to record personal characteristics, working patterns, drug and alcohol use (in the past six months), type and frequency of violence by clients (ever or in the past six months), and levels of attack reported to police. We contacted $156(65 \%)$ prostitutes in their place of work and $84(35 \%)$ through drop-in centres. We used SPSS to test for significance, and multivariate binary logistic regression analysis to identify variables most strongly associated with violence experienced ever or in the past six months.

The table shows that prostitutes working outdoors were younger, involved in prostitution at an earlier age, reported more illegal drug use, and experienced significantly more violence from their clients than those working indoors (81\% (93 of 115) v 48\% (60 of $\left.125), \chi^{2}=29.2, \mathrm{df}=1, \mathrm{P}<0.0001\right)$. Prostitutes working outdoors most frequently reported being slapped, punched, or kicked, whereas prostitutes working 